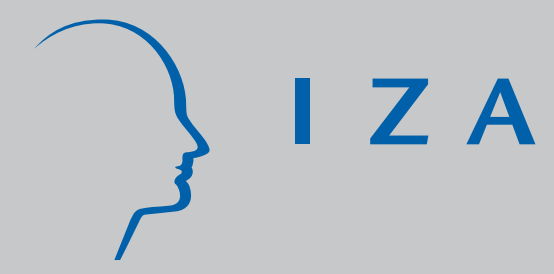

IZADP No. 2627

Wage Persistence and Labour Market Institutions: An Analysis of Young European Workers

Antonio Menezes

Dario Sciulli

J osé Cabral Vieira

February 2007 


\title{
Wage Persistence and Labour Market Institutions: An Analysis of Young European Workers
}

\author{
Antonio Menezes \\ University of the Azores and CEEApIA \\ Dario Sciulli \\ University of the Azores and CEEApIA \\ José Cabral Vieira \\ University of the Azores, CEEApIA and IZA
}

Discussion Paper No. 2627

February 2007

IZA

P.O. Box 7240

53072 Bonn

Germany

Phone: +49-228-3894-0

Fax: +49-228-3894-180

E-mail: iza@iza.org

Any opinions expressed here are those of the author(s) and not those of the institute. Research disseminated by IZA may include views on policy, but the institute itself takes no institutional policy positions.

The Institute for the Study of Labor (IZA) in Bonn is a local and virtual international research center and a place of communication between science, politics and business. IZA is an independent nonprofit company supported by Deutsche Post World Net. The center is associated with the University of Bonn and offers a stimulating research environment through its research networks, research support, and visitors and doctoral programs. IZA engages in (i) original and internationally competitive research in all fields of labor economics, (ii) development of policy concepts, and (iii) dissemination of research results and concepts to the interested public.

IZA Discussion Papers often represent preliminary work and are circulated to encourage discussion. Citation of such a paper should account for its provisional character. A revised version may be available directly from the author. 
IZA Discussion Paper No. 2627

February 2007

\section{ABSTRACT}

\section{Wage Persistence and Labour Market Institutions: An Analysis of Young European Workers}

This paper investigates the effects of labour market institutions on wage persistence among young European workers at the beginning of their careers. We use ECHP data from 1995 to 2001 for 13 EU countries and estimate a three-level random intercept probit model that allows for unobserved heterogeneity both at the individual and country level. Overall, we find that labour market institutions explain wage persistence. In particular, we find that a high level of employment protection legislation and a high level of bargaining centralization increase wage persistence.

JEL Classification: J31, C23, J5

Keywords: wage persistence, labour market institutions, unobserved heterogeneity

Corresponding author:

José Cabral Vieira

Department of Economics and Management

University of the Azores

9500 Ponta Delgada

Portugal

E-mail: josevieira@notes.uac.pt 


\section{Introduction}

Wage mobility has constituted a matter of concern in the last years, as it is perceived as an important issue from a welfare perspective, particularly with reference to wage inequality and social mobility. Recently, several authors have studied the relationship between labour market institutions and wage mobility. Theoretical models predict that strict labour market regulations reduce wage mobility. For instance, a high level of employment protection legislation (EPL) leads to a lower job turnover rate, and, thus, to a decline in a major source of wage mobility (Bertola, 1990). In addition, the existence of minimum wage legislation and a high level of bargaining centralization contribute to compress the wage distribution (OECD, 2004).

Quite interestingly, recent empirical studies do not confirm the above mentioned theoretical predictions. In particular, countries with different labour market institutions experience similar wage mobility levels (see, among others, Burkhauser et al. 1997, Aaberge et al. 2002 and Cardoso 2006). We contribute to this literature with a novel microeconometric study that controls for observed individual and job related characteristics, observable labour market institutions and allows for unobservable heterogeneity at both the individual and country level. We use a three-level random intercept probit model as our benchmark model. We focus on young European workers at the beginning of their careers for, at least, two reasons. First, young workers constitute a disadvantaged group in the sense that they are over represented in low paid jobs. In addition, young workers experiment more precarious employment and higher job turnover that, in turn, conditions wage persistence and human capital accumulation (Mincer and Ofek, 1982). Hence, uncovering the determinants of wage persistence may be relevant to understand structural differences in labour market experiences of different worker groups, both within and across countries. Second, by focusing on young workers at the beginning of their careers allows a simpler treatment of the socalled initial condition problem. When the beginning of the observation period does not coincide with the beginning of the stochastic process generating wage experiences, potential non-exogeneity of the conditioning starting state may bias parameter estimates (Heckman, 1981). In our sample, we do observe the initial wage values and, hence, the initial conditional problem does not arise. ${ }^{1}$

For the sake of international analysis, wage persistence is defined with respect to a deciles transition matrix at the European level and we use the European Community Household Panel (ECHP) dataset as it contains homogeneous variables and a uniform data gathering methodology across countries.

\footnotetext{
${ }^{1}$ Previous studies on wage mobility tackled the initial condition problem by dealing with the endogeneity of the initial conditions using bivariate probit models (Cappellari, 2000 and Vieira, 2005). However, it should be noted that such bivariate probit models do not take into account unobserved heterogeneity, unlike our benchmark model.
} 
The remainder of the paper is organized as follows. Section 2 presents the statistical model. Section 3 describes the data. Section 4 discusses results. Finally, section 5 concludes.

\section{Econometric Specification}

Our econometric specification consists in a probit model with unobserved heterogeneity at both the individual and country level. As observations within groups are more likely to be correlated than observations from different groups, failure to control for heterogeneity may lead to inconsistent estimates and misleading inferences. Hence, we implement a Generalized Linear Latent and Mixed Models program (Rabe-Hesketh, Pickles and Skrondal, 2004, Rabe-Hesketh, Skrondal and Pickles, 2005 ) and estimate a three-level random intercept probit model, taking into account the nesting of individuals in their country of origin. We compute wage persistence in terms of a deciles transition matrix computed at the European level. ${ }^{2}$

Let $p_{r d} \geq 0$ be the probability that an individual moves from the decile $r$ to the decile $d$ one period later. We define the $m \times m$ transition matrix, $P:=\left[p_{r d}\right]$, with $\sum_{s=1}^{10} p_{r d}=\sum_{r=1}^{10} p_{r d}=1$. Let $y_{j i k}$ be the binary response variable, $j$ denote a level-1 unit (the unit of observation, i.e. the observed elementary transition between $r$ and $d$ ) with $j=1,2, \ldots, J$; $i$ a level-2 unit with $i=1,2, \ldots, N$ (i.e. the individuals) and $k$ a level-3 unit, with $k=1,2, \ldots, K$ (i.e. the countries). The response variable for the individual $i$ living in country $k$ is defined as:

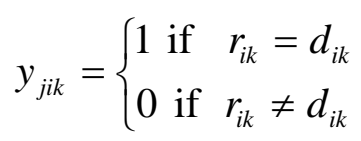

Thus, wage persistence is defined as the degree of immobility (year by year) in the transition matrix and is identified by the diagonal elements of the matrix.

Let $x_{j i k}$ be a vector of time-varying individual and job-related characteristics, $x_{i k}$ a vector of non time-varying individual and job-related characteristics, $x_{k}$ a vector of institutional characteristics of the labour markets; $\beta_{0}, \beta_{1}, \beta_{2}$ and $\beta_{3}$ are vectors of unknown parameters and, finally, $\alpha_{i k}{ }^{(2)}$ is the random intercept for individual $i$ in country $k$ and $\alpha_{k}{ }^{(3)}$ is the random intercept for country $k$. Denoting the link function by $g$, the generalized non-linear three level model can be defined as:

$$
g\left[E\left(y_{j i k} \mid x_{j i k}, x_{i k}, x_{k}, \beta_{0}, \beta_{1}, \beta_{2}, \beta_{3}, \alpha_{i k}^{(2)}, \alpha_{k}^{(3)}\right)\right]=\eta_{j i k}=\beta_{0}+\beta_{1} x_{j i k}+\beta_{2} x_{i k}+\beta_{3} x_{k}+\alpha_{i k}^{(2)}+\alpha_{k}^{(3)}
$$

\footnotetext{
${ }^{2}$ Parker and Gardner (2002) applied a similar approach.
} 
The probability of experimenting wage persistence may be expressed as:

$$
\theta_{j i k}=\operatorname{Pr}\left(y_{j i k}=1 \mid X, \beta, \alpha_{i k}^{(2)}, \alpha_{k}^{(3)}\right)=\frac{\exp \left(\beta_{0}+\beta_{1} x_{j i k}+\beta_{2} x_{i k}+\beta_{3} x_{k}+\alpha_{i k}^{(2)}+\alpha_{k}^{(3)}\right)}{1+\exp \left(\beta_{0}+\beta_{1} x_{j i k}+\beta_{2} x_{i k}+\beta_{3} x_{k}+\alpha_{i k}^{(2)}+\alpha_{k}^{(3)}\right)}
$$

The likelihood function, integrating out the random terms, reads:

$$
L(\beta, \Omega)=\prod_{k=1}^{K} \int_{-\infty}^{+\infty}\left(\prod_{i=1}^{N} \int_{-\infty}^{+\infty}\left(\prod_{j=1}^{J}\left(\theta_{j i k}\right)^{y_{j i k}}\right) \varphi^{(2)}\left(\alpha_{i k}\right) d \alpha_{i k}\right) \varphi^{(3)}\left(\alpha_{k}\right) d \alpha_{k}
$$

where $\Omega=\operatorname{Var}(\alpha)$ and $\varphi^{(2)}$ and $\varphi^{(3)}$ are the density functions of the random effects. As usual, we assume that the random effects are normally distributed with zero mean. The likelihood function is approximated via a Gauss-Hermite quadrature and is maximized by the Newton-Raphson method.

\section{Data}

We use a sub-sample from seven-waves, 1995-2001, of the ECHP; this is a standardized annual longitudinal survey designed by Eurostat, comprising socio-demographic information on individuals and their families and job related variables (see Peracchi 2002 for additional details on the ECHP). Since the ECHP wages are in nominal terms and at national currency values, we transform them with ECU/EURO exchange rates and comparative price level indices ${ }^{3}$, and, thus, make them comparable across countries.

We select only individuals who had their first job experience after 1994, in 13 European countries (EU except Sweden and Luxembourg). Only non self-employed workers, aged between 16 and 35, working more than 15 hours per week, with non-missing information were considered. This selection leaves us an unbalanced panel composed by 9837 observations and 4711 individuals.

We control the following personal characteristics: age, gender, education, marital status, presence of children, health status. In addition, we introduce the following job related covariates: type of contract, public or private sector, part-time work, size of firm and industry. Finally, we consider an indicator of job changes, as it may be an important source of wage mobility (Gottschalk and Moffitt, 1994). We also control for the starting decile. In fact, wage persistence is higher at the extreme deciles of the wage distribution, implying that wage persistence takes a U shaped form, as Figure 1 illustrates. As Dickens (2000) argues, this could be an artefact of computing mobility in

\footnotetext{
${ }^{3}$ ECU/EURO exchange rates are provided by European Commission DG II, while comparative price level indices are provided by Eurostat.
} 
terms of deciles transition matrices: modal values are associated with middle deciles, while extreme deciles are characterized by lower wage frequencies but larger wage ranges.

$<$ Insert Figure 1 here $>$

Finally, we investigate the effects of labour market institutions on wage persistence controlling for the level of employment protection legislation (EPL), the level of bargaining centralization and the existence of minimum wage legislation. The level of EPL is measured by the OECD indicator of the strictness of overall EPL (OECD, 2004), in its second version, as it provides a broad measure of EPL by including specific requirements for collective dismissals. ${ }^{4}$ We use the OECD indicator of bargaining centralization ${ }^{5}$ for the period 1995-2000 and construct three dummies. Low level of centralization includes countries where company/plant level bargaining is predominant and a combination of industry and company/plant level bargaining coexist, but an important share of employees are covered by company level bargaining. Medium level of centralization indicates countries where industry level bargaining is largely predominant. High level of centralization flags countries where industrial level bargaining and recurrent central-level agreements coexist, and countries where central level agreements override. Finally, we include a dummy variable to indicate the existence of minimum wage legislation. Table 1 reports descriptive statistics, in the usual manner.

\section{$<$ Insert Table 1 here $>$}

\section{Results}

Table 2 presents wage persistence across countries. The incidence of wage persistence is lower among young workers at the beginning of their job careers in comparison with the overall working population, a result in line with previous findings in the literature (Cardoso, 2006). This finding suggests that job turnover, a phenomenon especially acute among young workers, plays a key role in explaining wage persistence (Gottschalk and Moffitt, 1994). Several factors may explain cross country differences in wage persistence. First, the distribution of individuals and job-related workers’ observable characteristics varies across countries. Second, different institutions are likely to influence wage persistence. Finally, disparities in purchasing power may influence wage persistence. In fact, workers living in countries with extreme levels of purchasing power are likely to be allocated in the extreme deciles of the wage distribution, with higher immobility. In fact, this

\footnotetext{
${ }^{4}$ Using Overall EPL indicator version 1 that allows changes over time but excludes regulations on collective dismissals results remain substantially unchanged.

${ }^{5}$ OECD does not provide information about level of bargaining centralization in Greece. However, Ioakimoglou, Kouzis and Soumeli, (INE/GSEE-ADEDY, www.eiro.eurofound.ie), highlight that national occupational level and industry level are considered to be the most important levels at which wages are formed.
} 
reasoning may explain why Portugal and Denmark - the poorest and richest countries in the sample, respectively - experience the highest levels of wage persistence.

$<$ Insert Table 2 here $>$

Table 3 presents the estimation results. We show, for comparison purposes, estimates obtained applying a pooled probit model with robust standard errors, a probit model with random effects at the individual level and, finally, our benchmark probit model allowing for random effects both at the individual and country level. For brevity, we focus on our benchmark model. Individual and job-related observable characteristics explain wage persistence. Age shows a U effect, with wage persistence reaching a minimum for workers aged 22 years old. Being a male reduces wage persistence. Having a high educational level reduces wage persistence. Having a part-time job, working in the public sector and being employed with a temporary contract all decrease wage persistence. As expected, job changes reduce wage persistence. Working in firms of small-medium size reduces wage persistence. Clerks, skilled agricultural, fishery and craft workers, plant and machine operators and assemblers are less likely to experiment wage persistence than workers employed in elementary job activities. The dummy variables that flag the starting wage deciles present the expected signs (not shown for brevity).

$<$ Insert Table 3 here $>$

Our findings support the idea that stricter labour market regulations increase wage persistence $^{6}$. In particular, we find that a higher level of EPL significantly increases wage persistence. The existence of minimum wage legislation, however, has no significant effect on wage persistence. This result may be spurious in the sense that countries where there is no formal minimum wage legislation may have different provisions that, in practice, act as binding arrangements for wage floors (Italy is a remarkable example; see OECD, 2004). High level of bargaining centralization increases wage persistence with respect to countries characterized by medium level of bargaining centralization. Low level of bargaining centralization has a negative but not significant effect on wage persistence in our benchmark model where we control for heterogeneity at the individual and country. However, in both models that do not take into account of heterogeneity at the country level one finds that low level of bargaining centralization has a significant and positive effect on wage persistence. We take this result as suggestive of the importance of controlling for heterogeneity in order to avoid misleading inferences.

\section{Conclusions}

\footnotetext{
${ }^{6}$ We find similar results when we compute wage persistence taking into account deciles transition matrices for each country separately.
} 
This paper investigates the effects of labour market institutions on wage persistence among young European workers at the beginning of their job careers. Applying a three-level random intercept probit model to ECHP data, we find that individual and job-related observable and unobservable characteristics explain wage persistence. In particular, we find that high educational level and job mobility significantly reduce wage persistence, and, concomitantly, enhance social mobility. We find that more regulated labour markets - with high EPL and a high level of bargaining centralization - experience higher wage persistence, in line with theoretical predictions. However, we do note that it is important to control for unobserved heterogeneity at the country level, in order to capture the role of country unobservable characteristics and to avoid misleading inferences and inconsistent estimates.

\section{References}

Aaberge, R., A. Bjorklund, M. Jantti, M. Palme, P.J. Pedersen, N. Smith and T. Wennemo, 2002, Income inequality and income mobility in the Scandinavian countries compared to the United States, Review of Income and Wealth 48, 443-469.

Bertola, G., 1990, Job security, employment and wages, European Economic Review 34, 851-886.

Buchinsky, M. and J. Hunt, 1999, Wage mobility in the United States, Review of Economics and Statistics 81, 351-368.

Burkhauser, R.V., D. Holtz-Eakin, and S. E. Rhody, 1997. Labor earnings mobility and inequality in the United States and Germany during the growth of the 1980s, International Economic Review 38, 775- 794;

Cappellari, L., 2000, Low-wage mobility in the Italian labour market, International Journal of Manpower 21, 264-290.

Cardoso, A.R., 2006, Wage mobility: do institutions make a difference?, Labour Economics 13, 387-404.

Dickens, R., 2000, Caught in a trap? Wage mobility in Great Britain: 1975-1994, Economica 67, 477-497. 
Gottschalk, P. and R. Moffitt, 1994, The growth of earnings instability in the U.S. labour market, Brookings Papers on Economic Activity 2, 217-272.

Heckman, J.J., 1981, Heterogeneity and state dependence, in: S. Rosen, eds., Studies in Labour Markets. (Chicago University Press, Chicago).

Mincer, J. and H. Ofek, 1982, Interrupted work careers: depreciation and restoration of human capital, The Journal of Human Resources 7, 3-24;

OECD, 2004, Employment Outlook, Chapters 2 and 3. (OECD, Paris).

Parker, S. C. and S. Gardner, 2002, International income mobility, Economics Letters 76, 179-187.

Peracchi, F., 2002, The European Community Household Panel: A Review, Empirical Economics 27, 63-90.

Rabe-Hesketh, S., A. Pickles and A. Skrondal, 2004, GLLAMMs Manual, U.C. Berkeley Division of Biostatistics Working Paper Series 160.

Rabe-Hesketh, S., A. Skrondal and A. Pickles, 2005, Maximum likelihood estimation of limited and discrete dependent variable models with nested random effects, Journal of Econometrics 128, 301323.

Vieira, J.C., 2005, Low-wage mobility in the Portuguese labour market, Portuguese Economic Journal 4, 1-14. 
Table 1

Descriptive Statistics

\begin{tabular}{|c|c|c|c|}
\hline Variable & Description of variables & Mean & Std. Dev. \\
\hline age & age & 23.859 & 3.711 \\
\hline male & gender & 0.504 & 0.500 \\
\hline married & marital status & 0.103 & 0.303 \\
\hline children & presence of children aged 0-15 & 0.106 & 0.308 \\
\hline no_children & no children & 0.894 & 0.308 \\
\hline badhealth & health status bad or very bad & 0.015 & 0.123 \\
\hline educ1 & low educational level & 0.273 & 0.446 \\
\hline educ2 & medium educational level & 0.386 & 0.487 \\
\hline educ3 & high educational level & 0.340 & 0.474 \\
\hline$\overline{\mathrm{pc}}$ & employed with permanent contract & 0.655 & 0.475 \\
\hline tc & employed with temporary contract & 0.248 & 0.432 \\
\hline other_relat & employed with other arrengement & 0.097 & 0.235 \\
\hline public & employed in public sector & 0.176 & 0.381 \\
\hline private & employed in private sector & 0.824 & 0.381 \\
\hline part_time & employed with part-time relationship & 0.059 & 0.236 \\
\hline full_time & employed with full-time relationship & 0.941 & 0.236 \\
\hline jobchange & job change & 0.185 & 0.388 \\
\hline $\operatorname{ludim0}$ & & 0.005 & 0.069 \\
\hline ludim1_4 & & 0.210 & 0.408 \\
\hline ludim5_19 & & 0.240 & 0.427 \\
\hline ludim20_49 & firm size & 0.159 & 0.366 \\
\hline ludim50_99 & & 0.109 & 0.311 \\
\hline ludim100_499 & & 0.141 & 0.348 \\
\hline ludim500 & & 0.136 & 0.343 \\
\hline legis_manager & legislator, senior officials and managers & 0.031 & 0.173 \\
\hline profess & professionals & 0.148 & 0.355 \\
\hline tech_assprof & technicians and associate professionals & 0.153 & 0.360 \\
\hline clerks & clerks & 0.191 & 0.393 \\
\hline serv_shop & service workers and shop and market sales workers & 0.176 & 0.381 \\
\hline skill_agr & skilled agricultural and fishery workers & 0.011 & 0.104 \\
\hline craft_trades & craft and related trades workers & 0.127 & 0.334 \\
\hline plant_mach & plant and machine operators and assemblers & 0.072 & 0.258 \\
\hline elem_occ & elementary occupations & 0.091 & 0.288 \\
\hline agriculture & & 0.019 & 0.136 \\
\hline industry & economic sector & 0.301 & 0.459 \\
\hline services & & 0.680 & 0.467 \\
\hline barglow & low level of bargaining centralization & 0.324 & 0.468 \\
\hline bargmed & medium level of bargaining centralization & 0.337 & 0.473 \\
\hline barghigh & high level of bargaining centralization & 0.339 & 0.474 \\
\hline minwage & existence of minimum wage legislation & 0.608 & 0.488 \\
\hline epl2 & level of employment protection legislation & 2.545 & 0.943 \\
\hline
\end{tabular}


Figure 1

Wage Persistence across Starting Decile

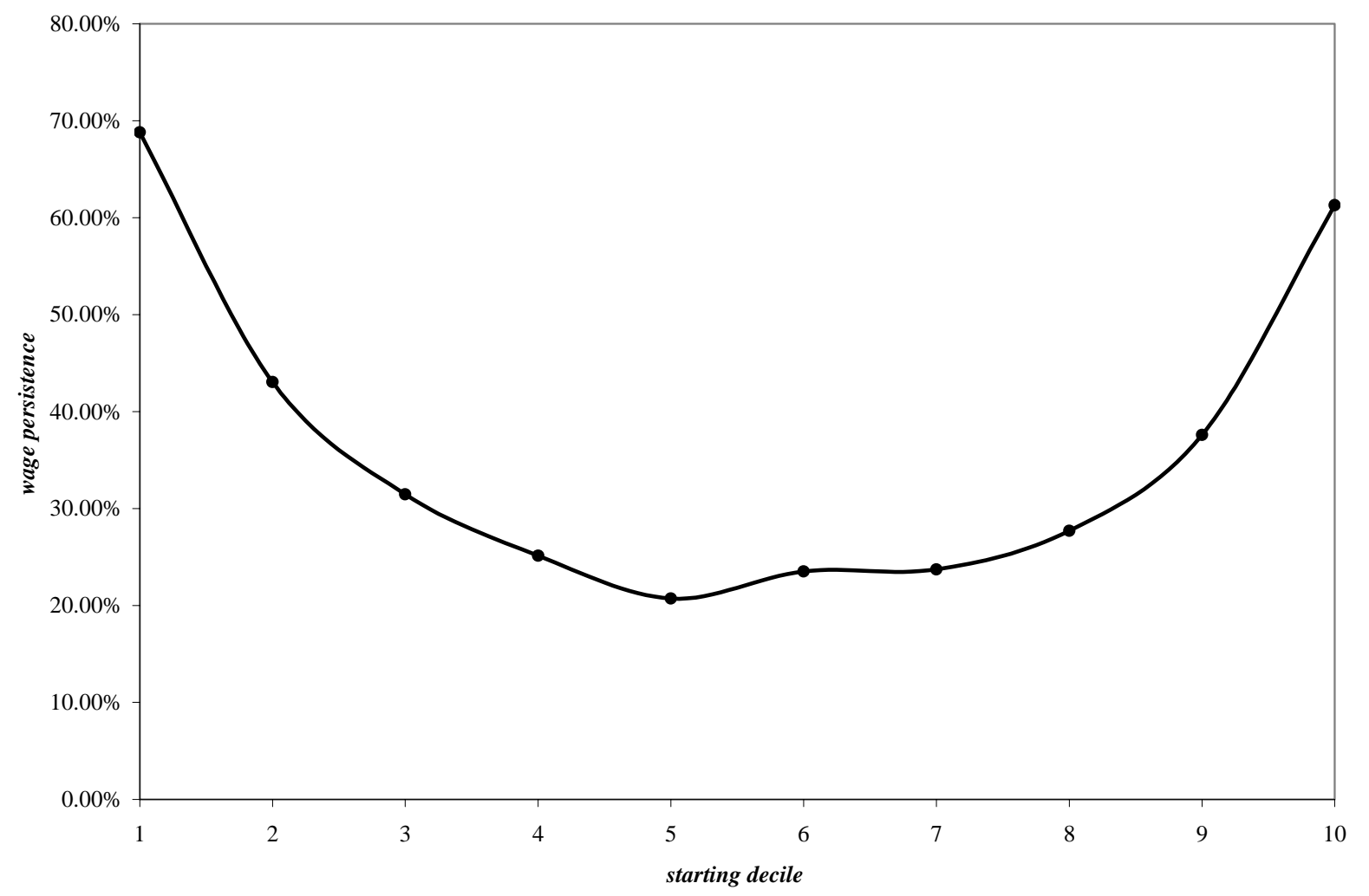

Table 2

Wage Persistence and Labour Market Institutions

\begin{tabular}{lcccc}
\hline Country & EPL & Min. wage & Centralization & Persistence \\
\hline Denmark & 1.8 & no & low & $50.00 \%$ \\
Netherlands & 2.3 & yes & medium & $31.16 \%$ \\
Belgium & 2.5 & yes & medium & $31.93 \%$ \\
France & 2.8 & yes & low & $28.10 \%$ \\
Ireland & 1.2 & since 2000 & high & $32.89 \%$ \\
Italy & 3.1 & no & low & $29.93 \%$ \\
Greece & 3.5 & yes & high & $39.00 \%$ \\
Spain & 3.0 & yes & medium & $27.11 \%$ \\
Portugal & 3.7 & yes & high & $62.14 \%$ \\
Austria & 2.4 & no & medium & $28.57 \%$ \\
Finland & 2.2 & no & high & $26.89 \%$ \\
Germany & 2.6 & no & medium & $29.41 \%$ \\
UK & 1.0 & since 1999 & low & $38.35 \%$ \\
\hline UE-13 & \multicolumn{5}{c}{}
\end{tabular}

Source: EPL and Level of Bargaining Centralization, OECD (2004)

Existence of Minimum Wage Legislation, OECD Labour Market Statistics, www1.oecd.org 
Table 3

Estimation Results

\begin{tabular}{|c|c|c|c|c|c|c|c|c|c|}
\hline \multirow[b]{2}{*}{ covariates } & \multicolumn{3}{|c|}{ Pooled Probit } & \multicolumn{3}{|c|}{ Probit RE $i$ level } & \multicolumn{3}{|c|}{ Probit RE $i$ and $k$ level } \\
\hline & $\mathrm{b}$ & r.s.e. & & $\mathrm{b}$ & s.e. & & $\mathrm{b}$ & s.e. & \\
\hline age & -0.108 & 0.039 & $* * *$ & -0.121 & 0.046 & $* * *$ & -0.086 & 0.052 & * \\
\hline age2 & 0.002 & 0.001 & $* * *$ & 0.002 & 0.001 & $* * *$ & 0.002 & 0.001 & $* *$ \\
\hline male & -0.141 & 0.029 & $* * *$ & -0.150 & 0.036 & $* * *$ & -0.174 & 0.043 & $* * *$ \\
\hline married & 0.067 & 0.045 & & 0.077 & 0.053 & & 0.038 & 0.061 & \\
\hline children & -0.078 & 0.045 & $*$ & -0.089 & 0.053 & $*$ & -0.080 & 0.062 & \\
\hline badhealth & 0.132 & 0.111 & & 0.165 & 0.119 & & 0.098 & 0.141 & \\
\hline educ2 & -0.125 & 0.036 & $* * *$ & -0.134 & 0.042 & $* * *$ & -0.062 & 0.050 & \\
\hline educ3 & -0.096 & 0.042 & $* *$ & -0.101 & 0.049 & $* *$ & -0.096 & 0.057 & $*$ \\
\hline $\mathrm{pc}$ & 0.125 & 0.030 & $* * *$ & 0.141 & 0.035 & $* * *$ & 0.162 & 0.040 & $* * *$ \\
\hline public & -0.050 & 0.040 & & -0.057 & 0.046 & & -0.118 & 0.056 & ** \\
\hline part_time & -0.276 & 0.061 & $* * *$ & -0.316 & 0.069 & $* * *$ & -0.310 & 0.082 & $* * *$ \\
\hline jobchange & -0.258 & 0.036 & $* * *$ & -0.270 & 0.040 & $* * *$ & -0.316 & 0.048 & $* * *$ \\
\hline ludim0 & -0.263 & 0.202 & & -0.314 & 0.231 & & -0.191 & 0.264 & \\
\hline ludim1_4 & -0.112 & 0.050 & $* *$ & -0.103 & 0.059 & $*$ & -0.086 & 0.067 & \\
\hline ludim5_19 & -0.123 & 0.049 & $* *$ & -0.126 & 0.057 & $* *$ & -0.107 & 0.067 & \\
\hline ludim20_49 & -0.149 & 0.050 & $* * *$ & -0.153 & 0.059 & $*$ & -0.155 & 0.068 & $* *$ \\
\hline ludim50_99 & -0.118 & 0.056 & $* *$ & -0.110 & 0.064 & $*$ & -0.095 & 0.073 & \\
\hline ludim100_499 & -0.117 & 0.052 & $* *$ & -0.127 & 0.059 & $* *$ & -0.109 & 0.068 & \\
\hline legis_manager & -0.104 & 0.092 & & -0.102 & 0.108 & & -0.143 & 0.124 & \\
\hline profess & -0.016 & 0.064 & & 0.010 & 0.076 & & 0.008 & 0.087 & \\
\hline tech_assprof & -0.086 & 0.060 & & -0.084 & 0.071 & & -0.118 & 0.081 & \\
\hline clerks & -0.165 & 0.057 & $* * *$ & -0.160 & 0.068 & $* *$ & -0.208 & 0.078 & $* * *$ \\
\hline serv_shop & -0.081 & 0.057 & & -0.083 & 0.068 & & -0.102 & 0.078 & \\
\hline skill_agr & -0.370 & 0.153 & $* *$ & -0.375 & 0.183 & $* *$ & -0.381 & 0.214 & $*$ \\
\hline craft_trades & -0.144 & 0.059 & $* *$ & -0.153 & 0.070 & $* *$ & -0.180 & 0.081 & $* *$ \\
\hline plant_mach & -0.161 & 0.067 & $* *$ & -0.161 & 0.079 & $* *$ & -0.181 & 0.092 & $* *$ \\
\hline industry & -0.129 & 0.115 & & -0.133 & 0.139 & & -0.127 & 0.161 & \\
\hline services & -0.197 & 0.114 & $*$ & -0.200 & 0.138 & & -0.218 & 0.160 & \\
\hline barglow & 0.266 & 0.040 & $* * *$ & 0.304 & 0.047 & $* * *$ & -0.026 & 0.067 & \\
\hline barghigh & 0.440 & 0.034 & $* * *$ & 0.490 & 0.042 & $* * *$ & 0.329 & 0.056 & $* * *$ \\
\hline minwage & 0.190 & 0.033 & $* * *$ & 0.200 & 0.038 & $* * *$ & 0.046 & 0.048 & \\
\hline epl2 & 0.059 & 0.018 & $* * *$ & 0.070 & 0.022 & $* * *$ & 0.127 & 0.026 & $* * *$ \\
\hline constant & 1.172 & 0.488 & $* *$ & 1.226 & 0.581 & $* *$ & 0.833 & 0.671 & \\
\hline $\mathrm{J}$ & & 37 & & & 337 & & & 37 & \\
\hline $\mathrm{N}$ & & & & & 711 & & & 11 & \\
\hline K & & & & & & & & 3 & \\
\hline Log-likelihood & & 2.548 & & & 8.408 & & & 0.702 & \\
\hline $\operatorname{Var}(\alpha) i$ level & & & & 0.496 & 0.032 & $* * *$ & 0.575 & 0.067 & $* * *$ \\
\hline $\operatorname{Var}(\alpha) k$ level & & & & & & & 0.353 & 0.065 & **** \\
\hline
\end{tabular}

All models also include control for starting decile.

*** Significant at $1 \%$

** Significant at 5\%

* Significant at $10 \%$ 